\title{
The impact of UK Soft Drinks Industry Levy on manufacturers' domestic turnover
}

Authors: Cherry Law ${ }^{1}$, Laura Cornelsen ${ }^{1}$, Jean Adams ${ }^{2}$, David Pell ${ }^{2}$, Harry Rutter ${ }^{3}$, Martin White ${ }^{2}$, Richard Smith ${ }^{4}$

${ }^{1}$ Faculty of Public Health \& Policy, London School of Hygiene \& Tropical Medicine

${ }^{2}$ Centre for Diet and Activity Research, MRC Epidemiology Unit, University of Cambridge

${ }^{3}$ Department of Social \& Policy Sciences, University of Bath

${ }^{4}$ College of Medicine \& Health, University of Exeter

\begin{abstract}
In March 2016, the UK government announced the Soft Drinks Industry Levy (SDIL) which came into effect in April 2018. In common with the reaction to sugar-sweetened beverage (SSB) taxes in other countries, the SDIL announcement was met with strong industry opposition, with claims that it would harm their profits. The SDIL was designed to incentivise reformulation of SSBs by providing a 2-year delay between the announcement and the enforcement of the levy, and adopting a two-tiered rate based on the sugar content of the drinks. Using interrupted time series analysis, this paper examines how the domestic turnover of UK soft drinks manufacturers changed after the announcement and the implementation of the SDIL. Our results show some evidence of a short-term negative impact of the SDIL announcement on the domestic turnover of the UK soft drinks manufacturers. This effect, however, did not continue post-implementation. These findings suggest that manufacturers were, to a large extent, able to mitigate the effects of levy before it came into effect.
\end{abstract}

Keywords: soda tax, soft drinks industry levy, tax impact, sugar

Funding: Evaluation of the SDIL is funded by the UK National Institute for Health Research, Public Health Research programme [Grant numbers: 16/49/01 \& 16/130/01]. LC is funded by an MRC Fellowship Grant (MR/P021999/1). The views expressed are those of the author(s) and not necessarily those of the MRC, NHS, NIHR or the Department of Health.

Conflict of interest: MW is Director of NIHR's Public Health Research Programme. All other authors report no conflicts of interest. 


\section{Background}

Sugar-sweetened beverages (SSBs) have been considered as a dietary contributor to excessive weight gain as well as increased risk of obesity, type 2 diabetes and other non-communicable diseases (NCDs) (Imamura et al. 2015; Xi et al. 2015; Malik et al. 2013). In recent years, taxation of SSBs has received growing attention among policymakers in many countries to discourage the consumption of SSBs and thus improve public health and reduce the societal health cost (Cawley et al. 2019; Allcott et al., 2019). Such policies, while widely supported by the public and health professionals (Public Health England 2015; Pell et al. 2019), have generally met with strong opposition from the soft drinks industry with claims that it will result in economic losses to the industry, and therefore also have negative consequences overall on economies (Niederdeppe et al. 2013; Powell et al. 2014; Backholer and Martin 2017).

Currently, there is limited real-world evidence of the direct impact of SSB taxes on the soft drinks manufacturing industry. Some studies have looked at the tax impacts on domestic soft drinks manufacturing sales and employment. Colchero et al. (2016) used national data from soft drinks manufacturers to assess changes in volume of sales after the 1 peso per litre tax implemented by Mexico in 2014 and found a decrease of 7.3\% in sales of soft drinks per capita and an increase of $5.2 \%$ per capita sales of plain water in 2014-2015 compared to the pre-tax period (2007-2013). Using the same sales data from domestic production over a longer period from 2007 to 2017, Arteaga et al. (2018) found a smaller level effect of the tax of 3.8\%. ${ }^{1}$ Some studies also look into employment changes associated with the introduction of SSB taxes. Guerrero-López et al. (2017) found no significant changes in employment in Mexican manufacturing industries for beverages and nonessential energy dense food after the implementation of the tax on these products in 2014. In the US context, Lawman et al. (2019) examined the change in new monthly unemployment claim fillings following the introduction of the SSB tax in Philadelphia in 2017 compared to neighbouring counties. They found no statistically significant relative changes to unemployment claims in Philadelphia for soft drinks manufacturing industry.

These studies commonly undertook an interrupted time series analysis (ITSA) using industry level time series data to study the impact. ITSA is a quasi-experimental design commonly used to evaluate the effectiveness of population-level intervention where randomisation is not feasible. Its main advantage over alternative estimation methods is that it takes full advantage of the longitudinal nature of the data to estimate the actual changes in outcomes while controlling for pre-intervention trends (Kontopantelis et al. 2015). This paper extends previous research by examining how the domestic turnover of soft drinks manufacturers in the United Kingdom (UK) changed after the announcement and the implementation of the Soft drinks Industry Levy (SDIL) in the UK, in March 2016 and April 2018 respectively. In particular, if a statistically significant decrease in domestic turnovers after the implementation of SDIL was found, this would provide evidence in support of the claim that SDIL created losses to the soft drink manufacturing industry.

Analysis of the SDIL is especially important because, unlike the SSB taxes in many countries, it was focussed on producers rather than consumers. It was designed to incentivise reformulation of SSBs by providing a 2-year delay between the announcement and the implementation of the levy, and adopting a two-tiered rate based on the sugar content of the drinks: $£ 0.24$ per litre for drinks with $\geq 8 \mathrm{~g}$

\footnotetext{
${ }^{1}$ Colchero et al. (2016) assessed the SSB tax impacts with controls for seasonality and the global indicator of economic activity. While Arteaga et al. (2018) did not account for these factors, they included a pre-tax structural break in their estimation. These estimation differences may help explain the smaller magnitude of the tax impact found in the latter work.
} 
added sugar per $100 \mathrm{ml}$ and $\mathrm{f} 0.18$ per litre for drinks with $5-8 \mathrm{~g}$ added sugar per $100 \mathrm{ml}$. Drinks with less than $5 \mathrm{~g}$ of sugar per $100 \mathrm{ml}$ are excluded from the levy as are no added sugar fruit juices, drinks containing at least $75 \%$ milk or milk alternatives, alcohol and alcohol replacements, drinks sold as a powder, infant formula and drinks for special medical purposes. ${ }^{2}$ Small manufacturers and importers with sales less than 1 million litres of liable drinks a year are exempt from the levy. Exported SSBs are also exempt.

The SDIL announcement in March 2016 was met by strong opposition from the UK soft drinks industry (Penney et al. 2018). An industry-sponsored modelling study quickly followed suggesting that the SDIL could reduce the direct contribution of the soft drinks industry to the UK's Gross Domestic Product (GDP) by $£ 74$ million, of which $£ 19$ million would come from soft drinks manufacturing, $£ 24$ million from on-trade (where drinks are consumed in situ, such as bars, restaurants or other catering venues) and $\mathrm{f31}$ million from off-trade (where drinks are consumed outside the retail premises such as supermarkets) (Oxford Economics, 2016). However, the study focused narrowly on the implementation of the SDIL and did not account for the fact that the SDIL had an explicit objective to encourage the manufacturers to reformulate beverages to lower sugar content, a means by which they could avoid the levy altogether. The soft drinks industry indeed took this as an opportunity to reformulate many beverages to reduce their sugar content between 2016 and 2018. One estimate shows that, from 2015 to 2017, the sales weighed average sugar levels per $100 \mathrm{ml}$ of drinks included in the SDIL fell by $11 \%$ (Public Health England, 2018). That substantial reformulation took place is also evidenced by the Treasury lowering their estimations on how much revenue they would collect from the SDIL even before the levy came into effect (from $f 0.5$ billion a year in 2016 to $f 0.3$ billion a year in November 2017) (HM Treasury 2016, 2017). As the date of implementation approached in April 2018 , industry statements started to change in tone and were increasingly aligned with the policy and its objectives to ensure perceived profitability of the soft drinks sectors and their contribution towards the Government's goals (Penney et al. 2018). This reflects that both the announcement and implementation of the SDIL might have (differentially) affected domestic sales of the soft drinks manufacturers.

In line with previous studies in this area, this paper conducts an ITSA on UK manufacturers' domestic soft drinks turnover data (i.e. sales for consumption within the UK) ${ }^{3}$. These monthly turnover data provided by the Office of National Statistics (ONS) have two advantages. First, they capture both ontrade and off-trade sales. Most literature to date on the effect of SSB taxes on purchases or sales use either retail scanner data or consumer purchase data (Cawley et al. 2019). One limitation is that these data do not typically include the on-trade sales which are non-trivial. According to Euromonitor (2019), $48 \%$ of carbonated drinks were sold on-trade in 2016 ( $£ 2.86$ billion in 2016 prices), based on total sales value in the UK ( $£ 5.91$ billion). This highlights the importance of accounting for soft drinks purchased for out-of-home consumption in evaluating the impact of the SDIL on the soft drinks industry. Second, ONS provides turnover data for both domestic consumption and exports. While Colchero et al. (2016) and Arteaga et al. (2017) used total sales data from manufacturing industry surveys and thus accounted for both on-trade and off-trade sectors, their data included drinks that were consumed domestically as well as those that were exported. Estimate of the impacts of the SDIL based on total sales might therefore be biased if soft drinks manufacturers shifted their focus, after implementation, to export markets where the SDIL was not applied. With the ONS data, we are able to focus on domestic turnover and thus provide a more comprehensive estimate of the SDIL's impacts on the soft drinks manufacturers in the UK.

\footnotetext{
${ }^{2}$ Section A in the appendix provides examples of non-diet drinks under each levy category in March 2016.

${ }^{3}$ Available at

https://www.ons.gov.uk/economy/economicoutputandproductivity/output/datasets/monthlybusinesssurvey mbsturnoverinproductionindustries
} 
The aim of the current analysis is to detect if there was a statistically significant change (i.e. structural break) in the domestic turnover of UK soft drinks manufacturers after both the announcement and the implementation of the SDIL. This work adds to the strand of literature exploring the economic effects of SSB taxes on industry by providing evidence not only on the implementation effects on the GDP contribution of the soft drinks manufacturers but also the impact of the announcement. It also provides important evidence for policymakers to understand the direct impacts of SSB taxes on manufacturers and hence better manage industry reaction to proposals to implement them.

\section{Data}

\subsection{Monthly time series data on UK manufacturers' domestic turnover}

We obtained monthly time series data on UK manufacturers' domestic turnover from April 2010 to March 2019, from ONS. ONS produces these data from responses to the Monthly Business Survey (MBS) which asks companies for their total production volume in GBP ( $f$ ) and for the share within this that is exported ${ }^{4}$. From the answers to these questions, ONS derive domestic and export elements, which exclude value added taxes as well as the SDIL. These figures are used to construct a number of important economic measures, including the output measure of GDP, the Index of Production and the Index of Services (ONS 2017).

The data are provided according to the Standard Industrial Classification (SIC). This study focuses on SIC 1107 which is defined as "Manufacture of soft drinks; production of mineral waters and other bottled waters" (hereafter referred to as 'soft drinks' for brevity). This includes the production of soft drinks, bottled waters and non-alcoholic flavoured and/or sweetened waters, but excludes the manufacture of fruit and vegetable juice, milk-based drinks, coffee, tea, maté products (i.e. traditional South American caffeine-rich infused drinks), alcohol-based drinks, non-alcoholic wine, non-alcoholic beer and ice. Considering that bottled water may be a substitute for SSBs and these two types of drinks are under the same SIC code, the ONS data may not entirely accurately reflect the domestic turnover of SSB manufacturers. However, according to annual statistics obtained from UK manufacturers' sales by product (ProdCom) (table 1), unsweetened waters only constituted $9.6 \%$ of total soft drinks manufacture in the UK in 2017, decreasing to $8.8 \%$ in $2018^{5}$. This suggests that measurement bias from our estimate of soft drinks turnover is likely to be limited as over $90 \%$ of soft drinks turnover came from SSBs. In addition, as shown in table 2, firms with $70 \%$ share of the UK carbonated drinks market also had over $40 \%$ share of the UK bottled water market. This implies that even if the price of SSBs increases following a tax and consumers substitute to water that is produced by the same producer, revenues simply shift rather than fall away (Richardson, 2016). Hence, the use of combined turnover of water and SSBs does not prevent us from answering our research question which is whether the SDIL led to a structural change in the domestic turnover of SSB manufacturers in the UK, be it through direct effect of falling SSB sales or increasing sales of substitute products. Similarly, it is also not crucial to distinguish the turnover from high sugar drinks and low/no sugar drinks as they are often produced by the same manufacturers.

Table 1: Annual UK soft drinks manufacturers' sales by product in 2016-18 (in thousands GBP)

\begin{tabular}{lrrr}
\hline & 2016 Sales & 2017 Sales & 2018 Sales* \\
\hline Mineral waters and aerated waters, unsweetened & 379,638 & 408,262 & 415,160 \\
All soft drinks & $4,363,310$ & $4,266,543$ & $4,672,620$
\end{tabular}

\footnotetext{
${ }^{4}$ ONS surveys approximately 30,000 businesses every month using stratified simple random sampling in which the strata are based on the employment of the business and the SIC codes. Weights are updated monthly to reflect changes in the business population.

${ }^{5}$ ProdCom is an annual survey required under EU Commission Regulation to measure sales of products by UK manufacturers. It uses more disaggregated product classification than the SIC codes used by the MBS.
} 
*Provisional estimates obtained in July 2019. Note: These figures give the total sales of UK manufacturers and do not include sales from imported drinks. Source: UK manufacturers' sales by product survey

Table 2. UK Market shares of firms producing both bottled water and carbonated drinks in 2017-2018 (in litre volume sale)

\begin{tabular}{lcccc}
\hline & \multicolumn{2}{c}{ Carbonated drinks (\%) } & \multicolumn{2}{c}{ Bottled water (\%) } \\
\cline { 2 - 5 } & 2017 & 2018 & 2017 & 2018 \\
\hline Tesco Plc & 4.1 & 4.0 & 8.9 & 9.1 \\
J Sainsbury Plc & 2.1 & 2.0 & 6.2 & 6.5 \\
Asda Group Ltd & 2.6 & 2.4 & 5.4 & 5.3 \\
Britvic Soft Drinks Ltd & 19.1 & 20.3 & 1.9 & 1.9 \\
Barr (AG) Plc & 2.4 & 2.5 & 2.2 & 2.3 \\
Coca-Cola Enterprises Ltd & 39.8 & 40.5 & 3.2 & 3.3 \\
Nestlé Waters UK Ltd & 0.4 & 0.4 & 15.5 & 15.3 \\
Lucozade Ribena Suntory Ltd & 0.1 & 0.1 & 0.0 & 0.1 \\
Total market share in respective market & $\mathbf{7 0 . 7}$ & $\mathbf{7 2 . 2}$ & $\mathbf{4 3 . 3}$ & $\mathbf{4 3 . 7}$ \\
\hline
\end{tabular}

Source: Euromonitor (2019)

To account for changes in the overall economic environment in the UK through the study period, we generated a data series on non-food and drinks (NonFD) domestic turnover by UK manufacturers using the ONS data. Food and other drinks turnover were excluded to avoid estimation bias from the possible substitution effect caused by the increase in prices of SSBs due to the SDIL towards other foods and beverages. To create this series (NonFD), we subtracted the domestic sales of any food and drink manufacturers from the total domestic sales with the exception of data on the manufacture of vegetable and animal oils and fats (hereafter edible oils for brevity) and manufacture of grain mill products, starches and starch products (hereafter starch products for brevity) because data on these categories were separately available only from April 2013. As an attempt to understand the SDIL impacts on domestic sales volume (i.e. quantity), after accounting for possible price changes triggered by the SDIL, we also included the Retail Price Index (RPI) of soft drinks, obtained from ONS as an approximation of prices. ${ }^{6}$ We adjusted all data series for inflation using the Consumer Price Index (CPI), also obtained from ONS. ${ }^{7}$

One important note is that the ONS data on domestic turnover capture the contribution of UK manufacturers to GDP. We are, however, unable to infer from these data the impact of the SDIL on the profitability of the SSB industry, which could be an alternative important outcome to investigate in terms of understanding the broader impacts of the policy, but this would require further data on the costs of reformulation as well as profit margins of the industry.

\subsection{Descriptive statistics}

\footnotetext{
${ }^{6}$ ONS computes the RPI for soft drinks using transaction price data on larger range of products in comparison to the manufacturing turnover data: fruit squash, fruit juice, lemonade, bottled water, energy drink, mixer drink, diet and regular cola drinks and other fruit drinks. Using CPI for soft drink do not change the results in the current analysis.

${ }^{7}$ Available at https://www.ons.gov.uk/economy/inflationandpriceindices
} 
Table 3 gives the summary statistics of the turnover data series used in this study (in real terms) over the three periods: pre-announcement (April 2010 - February 2016), post-announcement (March 2016 - March 2018) and post-implementation period (April 2018 - March 2019). Overall, the soft drinks industry's contribution to the UK economy is relatively small in comparison to NonFD manufacturers. The Pre-SDIL average monthly domestic turnover of UK soft drinks manufacturers was $£ 323$ million, which was around $1.6 \%$ of that of the NonFD (i.e. $£ 19,993$ million). The relative contribution of the soft drinks manufacturers increased slightly to $1.9 \%$ in the post-SDIL period. It is also noteworthy, that the turnover of soft drinks increased at a faster rate than NonFD manufacturers in both postannouncement and post-SDIL periods.

To understand changes over years, we plotted the decomposition graph of the UK soft drinks manufacturers' domestic turnover in figure 1 . The solid vertical line indicates the month of the announcement of the SDIL (i.e. March 2016) while the dashed vertical line indicates the start of the SDIL implementation period (i.e. April 2018). Soft drinks turnover displays large seasonality with an overall upward trend. After the SDIL announcement, there appears to be some negative shocks, as suggested by the random component, while the trend remains positive. Figure 2 shows that the seasonal pattern of the NonFD domestic turnover differs from that of soft drinks. The rising trend suggests an overall growth in domestic sales in the UK.

Table 3 Average monthly UK manufacturers' domestic turnover over different periods (in $f$ millions)

\begin{tabular}{|c|c|c|c|c|c|c|}
\hline & & (1) & $(2)$ & (3) & (4) & (5) \\
\hline Data series & Data period & $\begin{array}{c}\text { Pre- } \\
\text { announcement } \\
\text { (Before } \\
3 / 2016 \text { ) }\end{array}$ & $\begin{array}{c}\text { Post - } \\
\text { announcement } \\
(3 / 2016- \\
3 / 2018)\end{array}$ & $\begin{array}{c}\text { Difference } \\
(2)-(1)\end{array}$ & $\begin{array}{c}\text { Post- } \\
\text { implementation } \\
(4 / 2018- \\
3 / 2019)\end{array}$ & $\begin{array}{c}\text { Difference } \\
(4)-(2)\end{array}$ \\
\hline Soft drinks & $1 / 2010-3 / 2019$ & 323 & 400 & $77(23 \%)$ & 460 & $60(15 \%)$ \\
\hline NonFD & $1 / 2010-3 / 2019$ & 19993 & 22735 & $2742(14 \%)$ & 24189 & 1454 (6\%) \\
\hline
\end{tabular}

Source: ONS. Note: All series are adjusted for inflation using CPI obtained from ONS. All difference estimates are statistically significant at $99 \%$ confidence level under a t-test. Figures in parentheses give the percentage of change.

Figure 1: UK soft drinks manufacturers' domestic turnover (in $f$ millions, CPI adjusted)

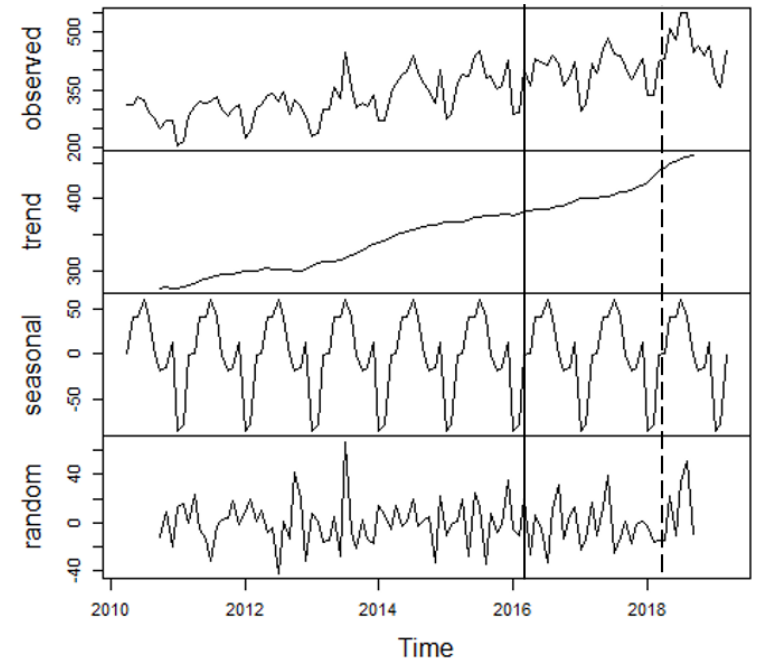

Note: The solid and dashed vertical lines indicate the SDIL announcement in March 2016 and the implementation in April 2018 respectively.

Figure 2: UK NonFD manufacturers' domestic turnover (in $f 100$ millions, CPI adjusted) 


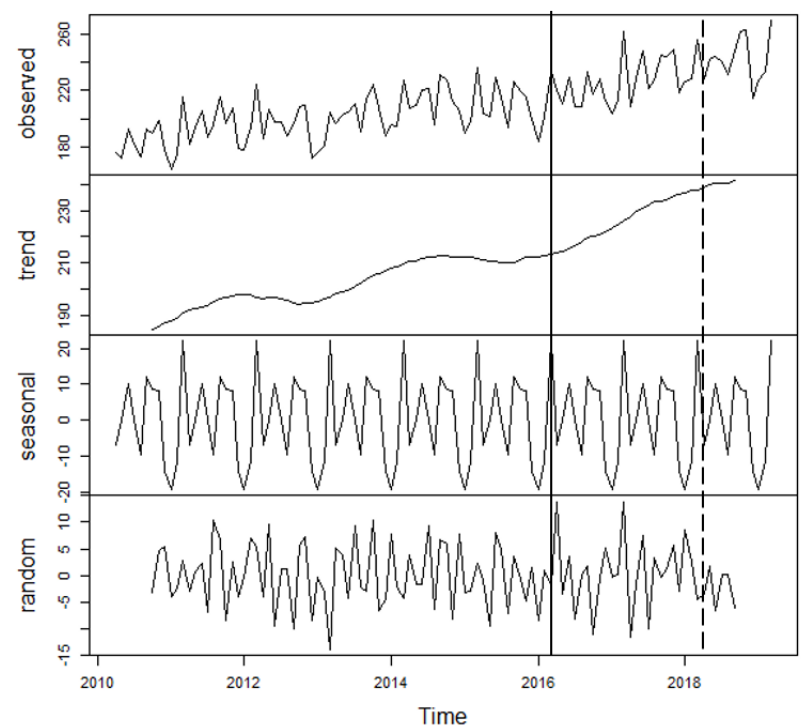

Note: The solid and dashed vertical lines indicate the SDIL announcement in March 2016 and the implementation in April 2018 respectively.

\section{Estimation method}

We use an ITSA to study if there were structural breaks in the trend and level of domestic turnover of soft drinks after the announcement and the implementation of the SDIL. The following equation using the Ordinary Least Square (OLS) method is estimated:

lnDrink $_{t}=\alpha+\beta_{1}$ trend $_{+}+\beta_{2}$ Announcement $_{t}+\beta_{3}$ Announcement $_{t} *$ trend $+\beta_{4}$ Implementation $_{t}+\beta_{5}$ Implementation $_{t} *$ trend $+\beta_{m} m+\beta_{c} \ln$ NonF $_{t}+\varepsilon_{t}$

Where $\operatorname{lnDrink}_{t}$ is logarithm of the UK soft drinks manufacturers' domestic turnover in real terms. trend is the time period variable, set to equal 0 in February 2016 (the month before the announcement of the SDIL), and trend $=-70 \ldots, 0 \ldots, 37 . \alpha$ represents the constant term and $\beta_{1}$ captures the underlying pre-SDIL trend. Two intervention dummy variables are used to capture the effects of the SDIL on soft drink domestic sales. The first is Announcement $t_{t}$, which takes the value of 1 over the post-announcement period (i.e. March 2016 to March 2018) and 0 otherwise. $\beta_{2}$ and $\beta_{3}$ give the level and trend changes in soft drinks turnover caused by the SDIL announcement

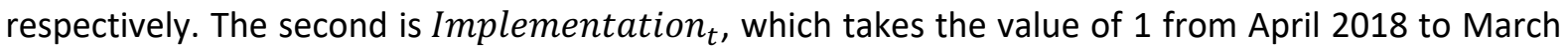
2019 and 0 otherwise. The level and trend effects of the SDIL implementation are thus captured by $\beta_{4}$ and $\beta_{5}$ respectively. $m$ represents a vector of dummy variables indicating the calendar months of the

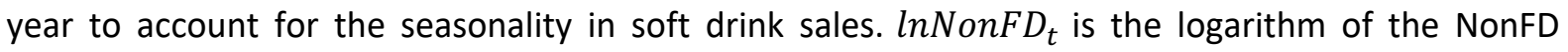
manufacturers' domestic turnover, which controls for the changes in the economic environment in the UK. $\varepsilon_{t}$ displays the error term. Additionally, we test the inclusion of a log-transformed RPI of soft drinks, $\ln R P I_{t}$, to account for price changes in soft drinks.

Since the outcome variable is log-transformed, the coefficients in the above equation can be interpreted as approximate percentage changes in the soft drinks manufacturers' domestic turnover.

Prior to estimation, we performed an augmented Dicker-Fuller (ADF) test on $\operatorname{lnDrink}, \operatorname{lnNonFD}$ and InRPI series to check the stationarity of these data series. The results are reported in the appendix and show no evidence of the existence of unit root with or without trend, with the exception of $\ln R P I$. 
Since the t-statistics for $\ln R P I$ are smaller than the $5 \%$ critical value for both ADF tests, it is a nonstationary series. Furthermore, there is a potential endogeneity bias between volume and prices, suggesting that results from estimations with $\ln R P I$ should be interpreted with caution.

A number of post-estimation residual tests are performed to ensure that our results are not subject to biases from the time-series characteristics of the data. ADF and Phillips-Peron tests (both without and with trend) were used to check whether the residuals of the regression contain unit root, in which case the coefficients of interest could be capturing a non-existing relationship (i.e. spurious regression). Additionally, the OLS assumption of independent distribution could be violated if the current value of the data series is determined by past observations. We therefore examined the residuals' autocorrelation and the partial autocorrelation plots. The Breusch-Godfrey test was also applied at alternative lags (i.e.1, 4, 6 and 12) to check for the existence of serial correlation. Finally, as a robustness check, we also estimated the effects of SDIL announcement and implementation on soft drinks turnover in separate models.

\section{Results}

\subsection{Joint impact of announcement and implementation}

We present the estimated announcement and implementation effects of the SDIL under different specifications in table 4. Model 1 gives the result of equation 1 without the control of InNonFD and shows that neither the announcement nor the implementation of the SDIL had any significant impact on the domestic turnover of soft drinks (level or trend). The SDIL effects remain statistically insignificant after controlling for the overall economic environment (model 2) which itself is positively associated with the NonFD turnover performance. Both models 1 and 2, however, show a significantly positive trend $(0.4 \%-0.5 \%)$ of domestic turnover of UK soft drinks manufacturers overall.

When the control for prices ( $\ln R P I)$ is added (model 3 ) we observe both a significant negative postannouncement change in soft drinks turnover level $(-5.6 \%, p=0.099)$ and trend $(-0.5 \%, p=0.016)$. As before, the estimated effect of the SDIL implementation is statistically insignificant. This suggests that there were no further substantial changes in soft drinks turnover after the implementation of the SDIL.

Table 4: The impacts of SDIL announcement and implementation on UK soft drinks manufacturers' domestic turnover

\begin{tabular}{lccc}
\hline Dependent variable: & \multicolumn{3}{c}{ Models } \\
\cline { 2 - 4 } InDrink $_{t}$ & $(1)$ & $(2)$ & $(3)$ \\
\hline Announcement $_{t}$ & -0.028 & -0.011 & $-0.056^{*}$ \\
& $(0.027)$ & $(0.030)$ & $(0.033)$ \\
Announcement $_{t} *$ trend & -0.000 & -0.002 & $-0.005^{* *}$ \\
& $(0.001)$ & $(0.002)$ & $(0.002)$ \\
Implementation $_{t}$ & -0.000 & 0.004 & -0.041 \\
& $(0.150)$ & $(0.129)$ & $(0.125)$ \\
Implementation $_{t} *$ trend & 0.000 & -0.001 & -0.001 \\
& $(0.005)$ & $(0.004)$ & $(0.004)$ \\
trend & $0.005^{* * *}$ & $0.004^{* * *}$ & $0.005^{* * *}$ \\
& $(0.000)$ & $(0.000)$ & $(0.001)$ \\
lnNonF $_{t}$ & & $0.753^{* * *}$ & $0.874^{* * *}$ \\
& & $(0.148)$ & $(0.135)$
\end{tabular}


$\operatorname{lnRPI} I_{t}$

Constant 19.497***

1.652

(0.017)

(3.509)

(3.230)

Month dummies

Yes

Yes

Yes

$\mathrm{N}$

108

108

108

Note: Robust standard errors in parentheses. ${ }^{*} p<0.1{ }^{* *} p<0.05 * * p<0.01$

In table 5, we first test the presence of unit roots in the residuals of models presented in table 4, using the ADF test and Phillips-Perron test. The $p$-values suggest that the residuals are stationary for all regressions, with or without trend $(p<0.001)$. The above SDIL-related coefficients are therefore not subject to the concern of spurious regression. Next, we checked if the residuals followed white noise through the autocorrelation and partial autocorrelation plots in Appendix C. With the exception for model 1 , there was no apparent pattern in the residuals. Model 1 displays significant spikes at lags 3 , 6 and 9. As a further check, the Breusch-Godfrey test results in table 5 suggest that the residuals of models 2 are serially uncorrelated. For other models, the null of no first-order serial autocorrelation are rejected. Model 3 has potential serial correlation bias in lag 12 , which is likely due to the $\ln R P I_{t}$ series showing non-stationarity.

Table 5: P-values for residual tests for unit roots and serial correlation for models in table 4

\begin{tabular}{lccc}
\hline & \multicolumn{3}{l}{ Models } \\
\cline { 2 - 4 } & $(1)$ & $(2)$ & $(3)$ \\
\hline 1. Dickey-Fuller test without trend & & -10.445 & -12.088 \\
Test statistics & -11.482 & $<0.001$ & $<0.001$ \\
P-value & $<0.001$ & & \\
2. Dickey-Fuller test with trend & & -10.418 & -12.046 \\
Test statistics & -11.445 & $<0.001$ & $<0.001$ \\
P-value & $<0.001$ & & \\
3. Phillips-Perron test without trend & & -10.466 & -12.378 \\
Test statistics & -11.428 & $<0.001$ & $<0.001$ \\
P-value & $<0.001$ & & \\
4. Phillips-Perron test with trend & & -10.452 & -12.366 \\
Test statistics & -11.400 & $<0.001$ & $<0.001$ \\
P-value & $<0.001$ & & \\
5. Breusch-Godfrey test (Prob> chi $^{2}$ ) & & 0.767 & 0.142 \\
Lags (1) & 0.375 & 0.347 & 0.140 \\
Lags (4) & 0.034 & 0.391 & 0.190 \\
Lags (6) & 0.013 & 0.045 \\
Lags (12) & 0.014 & 0.177 & \\
\hline
\end{tabular}

\subsection{Impact of announcement only}

Next, to check the robustness of the joint impact models, we tested the turnover impacts of the SDIL announcement and implementation separately. Since we were only interested in knowing if the SDIL announcement was followed by a structural change in soft drinks turnover, Announcement $t_{t}$ in table 6 is redefined to take the value of 0 from January 2010 to February 2016 and 1 from March 2016 
to March 2019. Using the entire data period, models A1 and A2 showed a negative level effect of the announcement on soft drinks turnover. This effect is, however, only statistically significant $(-7.3 \%$, $\mathrm{p}=0.031$ ) when $\operatorname{lnRPI}_{t}$ is controlled in model A2. To further isolate the effect of the SDIL implementation, models $A 3$ and A4 excluded data points from April 2018 onwards. The estimates of model A4, which controls for soft drinks prices, provide some evidence of a statistically negative association between the SDIL announcement and the level $(-5.8 \%, p=0.091)$ of turnover and strong evidence of a negative impact on the trend $(-0.5 \%, p=0.018)$ between April 2016 and March 2018., consistent with model 3 in table 4 . As before the negative trend post-announcement effectively halted the positive pre-announcement growth of the same magnitude $(0.5 \%, p<0.001)$.

Table 6: The impacts of SDIL announcement on UK soft drinks manufacturers' domestic turnover

\begin{tabular}{|c|c|c|c|c|}
\hline \multirow{3}{*}{$\begin{array}{l}\text { Data period } \\
\text { Dependent variable: } \ln \operatorname{Drink}_{t}\end{array}$} & \multicolumn{4}{|c|}{ Models } \\
\hline & \multicolumn{2}{|c|}{$\begin{array}{l}4 / 2010-3 / 2019 \\
\text { (full period) }\end{array}$} & \multicolumn{2}{|c|}{$\begin{array}{c}4 / 2010-3 / 2018 \\
\text { (up to SDIL implementation) }\end{array}$} \\
\hline & $\mathrm{A} 1$ & $\mathrm{~A} 2$ & $\mathrm{~A} 3$ & A4 \\
\hline \multirow[t]{2}{*}{ Announcement $_{t}$} & -0.037 & $-0.073^{* *}$ & -0.012 & $-0.058^{*}$ \\
\hline & $(0.023)$ & $(0.033)$ & $(0.030)$ & $(0.034)$ \\
\hline \multirow[t]{2}{*}{ Announcement $_{t} *$ trend } & 0.000 & 0.000 & -0.002 & $-0.005^{* *}$ \\
\hline & $(0.001)$ & (0.001) & $(0.002)$ & $(0.002)$ \\
\hline \multirow[t]{2}{*}{ trend } & $0.004 * * *$ & $0.004^{* * *}$ & $0.004^{* * *}$ & $0.005^{* * *}$ \\
\hline & $(0.000)$ & $(0.001)$ & $(0.000)$ & $(0.001)$ \\
\hline \multirow{2}{*}{$\operatorname{lnNonFD} D_{t}$} & $0.711^{* * *}$ & $0.754^{* * *}$ & $0.732 * * *$ & $0.875^{* * *}$ \\
\hline & $(0.138)$ & $(0.130)$ & $(0.161)$ & $(0.145)$ \\
\hline \multirow[t]{2}{*}{$\ln R P I_{t}$} & & $-0.419 *$ & & $-0.819 * * *$ \\
\hline & & $(0.248)$ & & $(0.241)$ \\
\hline \multirow[t]{2}{*}{ Constant } & 2.637 & 3.569 & 2.143 & 2.555 \\
\hline & (3.264) & (3.198) & (3.819) & (3.422) \\
\hline Month dummies & Yes & Yes & Yes & Yes \\
\hline$N$ & 108 & 108 & 96 & 96 \\
\hline
\end{tabular}

\subsection{Impact of implementation only}

The first two columns in Table 7 give the estimated effect of the SDIL implementation on soft drinks turnover using data from the full time series from April 2010 to March 2019. The latter two columns cover the same data period but exclude data points from the post-announcement period (March 2016 to March 2018), allowing comparison of soft drinks turnover in the post-implementation periods with that of the pre-announcement period. Across all models, there is no evidence for a statistically significant post-implementation change in the trend and level of soft drinks turnover. Importantly, the coefficients of the post-SDIL implementation trend are close to zero in all models, suggesting that the soft drinks turnover returned to the pre-announcement growth rate $(0.3-0.5 \%, p<0.001)$ after the implementation of the SDIL in April 2018.

Table 7: The impacts of SDIL implementation on UK soft drinks manufacturers' domestic turnover

\begin{tabular}{lcc}
\hline & \multicolumn{2}{c}{ Models } \\
\cline { 2 - 3 } Data period & $\begin{array}{c}4 / 2010-3 / 2019 \\
\text { (full period) }\end{array}$ & $4 / 2010-3 / 2019^{\wedge}$
\end{tabular}


excluding two years between

\begin{tabular}{|c|c|c|c|c|}
\hline \multirow[b]{2}{*}{ Dependent variable: $\ln \operatorname{Drink}_{t}$} & \multirow[b]{2}{*}{11} & \multirow[b]{2}{*}{12} & \multicolumn{2}{|c|}{ announcement and implementation) } \\
\hline & & & 13 & 14 \\
\hline \multirow{2}{*}{ Implementation $_{t}$} & 0.023 & 0.023 & 0.061 & 0.029 \\
\hline & $(0.129)$ & $(0.129)$ & $(0.037)$ & $(0.035)$ \\
\hline \multirow[t]{2}{*}{ Implementation $_{t} *$ trend } & 0.000 & 0.000 & 0.001 & 0.000 \\
\hline & $(0.004)$ & $(0.004)$ & $(0.004)$ & $(0.004)$ \\
\hline \multirow[t]{2}{*}{ trend } & $0.003 * * *$ & $0.003 * * *$ & $0.003 * * *$ & $0.005^{* * *}$ \\
\hline & $(0.000)$ & $(0.000)$ & $(0.000)$ & $(0.001)$ \\
\hline \multirow[t]{2}{*}{$\operatorname{lnNonF} D_{t}$} & $0.669 * * *$ & $0.670 * * *$ & $0.782^{* * *}$ & $0.947^{* * *}$ \\
\hline & $(0.131)$ & $(0.132)$ & (0.149) & $(0.131)$ \\
\hline \multirow[t]{2}{*}{$\ln R P I_{t}$} & & -0.052 & & $-0.907 * * *$ \\
\hline & & $(0.178)$ & & $(0.258)$ \\
\hline \multirow[t]{2}{*}{ Constant } & 3.616 & 3.838 & 0.955 & 1.258 \\
\hline & (3.115) & $(3.305)$ & (3.524) & (3.041) \\
\hline Month dummies & Yes & Yes & Yes & Yes \\
\hline $\mathrm{N}$ & 108 & 108 & 83 & 83 \\
\hline
\end{tabular}

Note: ^ Data points from 3/2016 to 3/2018 are excluded. Robust standard errors in parentheses. ${ }^{*} p<0.1{ }^{* *} p<0.05$ $* * * p<0.01$

Tables D1 and D2 in the Appendix provide the residual test results for the estimations in tables 6 and 7 respectively. The unit root test statistics suggest that the residuals of all models are stationary and hence the estimates are not subject to spurious regression. The Breusch-Godfrey tests do not reject the null hypothesis of no serial autocorrelation for all models at $95 \%$ confidence level. ${ }^{8}$ The results in tables 6 and 7 are consistent with table 4, suggesting that negative changes in soft drinks domestic turnover are only associated with the period between the announcement of the SDIL in 2016 and the implementation of the SDIL in 2018.

\section{Discussion \& conclusion}

As far as we are aware, this paper is the first to assess separately the impact of both the announcement and the implementation of a SSB tax on the domestic turnover of the UK soft drinks manufacturers. Regardless of whether the impacts of the announcement and implementation were estimated jointly or in separate ITSA models, there was some evidence of a statistically significantly impact on both the level $(-5.6 \%)$ and trend $(-0.5 \%)$ of turnover in the two-year period between the SDIL announcement and implementation, after controlling for overall trends in manufacturing as well as changes in the soft drinks prices. Implementation of the SDIL in April 2018 was not associated with any further changes in either the level or the trend in the turnover series. These findings were robust to spurious regression tests.

Unlike the industry-sponsored modelling study conducted by Oxford Economics (2016), we found no evidence of a loss in GDP contribution from the soft drinks industry after the implementation of the SDIL. There was, however, some evidence of a short-term negative impact of the SDIL announcement on the domestic turnover of soft drinks manufacturers. During the post-announcement period, turnover changes were unlikely to be caused by increases in prices as the RPI series, to the contrary, demonstrates a downward trend. Our findings thus imply that the negative impact during the two year post-announcement, pre-implementation period was likely to be driven by a decrease in volume

\footnotetext{
${ }^{8}$ For brevity, we do not report the autocorrelation and partial autocorrelation residual plots, which are available upon request.
} 
sold due to non-price related drivers. This is not surprising because some consumers may have been put off by changes in drink recipes, including in the taste, as many manufacturers reformulated their drinks by reducing sugar content to avoid the levy. For example, Lucozade Energy suffered from an initial loss of sales to its rival Red Bull as customers turned away from its new lower-sugar formula in 2017 (The Grocer 2018). However, the brand appeared to be recovering, having increased value sales by $12 \%$ in the 13-week period to January 2019 (The Grocer 2019).

Another potential pathway could be the signalling effect from the media coverage of the SDIL announcement and the relatively frequent coverage of the negative health impacts of (over)consuming sugar and sugar-sweetened beverages overall (Pell et al. 2019; Buckton et al. 2018; Buckton et al. 2019). As the SDIL is part of a wider package of policy instruments recommended by Public Health England in its Childhood Obesity Strategy, further research is needed to disentangle the relative importance of the SDIL announcement from changes due to other initiatives, such as Change4Life nutrition campaign (Public Health England 2017), in driving the changes in soft drinks domestic turnover.

As with any study there were some limitations of our methods. First, the data used in this paper captured the domestic turnover of the UK soft drinks manufacturers, which occurred in both on-trade and off-trade settings. We were, however, unable to infer from this data the impact of the SDIL of the profitability of the soft drinks industry. In particular, the announcement of the SDIL motivated many of the producers to reduce the level of sugar in their drinks. Further data on the costs of reformulation and compensatory marketing campaigns as well as profit margins of the manufacturers would be required to assess the impact of the SDIL on their profit. Second, the SDIL effects estimated in this analysis did not take into account the possible increase in GDP contribution through substitution effects. The stimulation study by Powell et al. (2014) found that a $20 \%$ SSB tax was associated with a close to zero net change in jobs in Illinois and California as declines in employment within the beverage industry were offset by new employment in the non-beverage industry and the government sector. Due to the limitation of ONS data on domestic turnover, it is not feasible to conduct the analysis of the SDIL impacts on substitute products. For example, ONS only provides combined turnover data of alcohol and tobacco industries but not alcoholic beverages alone. Hence, the loss in GDP from soft drinks manufacturing observed between April 2016 and March 2018 could be offset by increases in domestic turnover from non-soft drinks manufacturers. Third, our control measure of NonFD could be biased due to the inclusion of domestic turnover from edible oils and starch products industries. Using the turnover data after April 2013, we found that the turnover of these two industries were rather small. The trend of the NonFD measure did not change after accounting for these industries. This suggests that any measurement bias from our control measure is likely to be trivial.

As emphasised by UK government, the SDIL is not a tax on consumers. The intention is to encourage manufacturers to reformulate products and make their drinks healthier rather than necessarily to reduce consumption (HM Treasury 2016). Recent studies have found evidence in support of this reformation effect of the SDIL. Using annual sales data from 2015-2018, Bandy et al. (2020) showed the sale of sugars from soft drinks decreased by 30\% between 2015 and 2018, equivalent to a reduction in $4.6 \mathrm{~g}$ sugar per capita per day. They also found that the mean sugar content of soft drinks declined by $34 \%$ throughout the period, with the greatest decrease in 2017-2018. This implies that the SDIL acted as an extra incentive for industry to reformulate drinks. Similar results are seen in Scarborough et al. (2020) which collected data from the websites of the leading supermarkets in the UK. They showed that the proportion of potentially levy-eligible drinks with over $5 \mathrm{~g}$ sugar per $100 \mathrm{ml}$ had fallen by 19.8 percentage point from August 2015 to February 2018. While the reduction in sale of sugar is a positive sign that SDIL has improved the healthiness of beverages in the UK, further analysis is needed to confirm the full public health effect of the SDIL. In particular, marketing effort of 
the industry might have encouraged substitutions from SSBs to levy-exempted drinks that contain high level of sugar like fruit juices. Consumers may also switch to non-drink based sugar sources, such as chocolates, confectionary and biscuits.

Our findings, together with the above evidence of soft drink reformulation, imply that the delayed implementation of the SDIL seems to have made it possible for soft drinks manufacturers to avoid any potential losses by adapting to the levy through reformulating drinks and increasing the availability of non-levied products prior to the levy coming in to effect. Hence, the concerns about economic harm to industry voiced in advance of the introduction of the SDIL do not appear to have materialised. Indeed, while the total volume sales of soft drinks in the UK that are subject to the SDIL (i.e. contain more than $5 \mathrm{~g} / 100 \mathrm{ml}$ of sugar) fell by $50 \%$ between 2015 and 2018, the volume sales of low- and zerosugar drinks (i.e. $<5 \mathrm{~g} / 100 \mathrm{ml}$ ) rose by $40 \%$ and that of bottled water and products exempt from the SDIL also rose by $23 \%$ (Bandy et al. 2020).

This study provides valuable lessons for the structure and implementation of future health policy actions. Industry opposition is one of the key barriers in implementing SSB taxes. In the US, the food and beverage industry successfully lobbied state legislatures for pre-emption of SSB taxes (Pomeranz and Pertschuk 2019). As of 2018, Arizona, California, Michigan, and Washington enacted laws to prohibit localities to levy taxes on SSB. The SDIL showcases that SSB taxes do not necessarily cause significant losses to soft drink industry if the tax structure is carefully designed to motivate reformulation and thus achieve the goal of sugar reduction. Our findings thus serve as empirical evidence for health policy makers to defend against the claim of negative consequences overall on economies and thus manage industry opposition to SSB taxes. More broadly, our results also illustrate that by giving sufficient time for industry to react to policy changes, governments can potentially achieve the goal of improving public health while minimising negative impacts on industry.

\section{Reference}

Allcott, H., B.B. Lockwood, and D. Taubinsky. 2019. "Should We Tax Sugar-Sweetened Beverages? An Overview of Theory and Evidence." Journal of Economic Perspectives 33(3):202-227.

Arteaga, J.C., D. FLores, and E. Luna. 2017. "The effect of a soft-drink tax in Mexico: a time series approach." MPRA Paper No. 80831,

Backholer, K., and J. Martin. 2017. "Sugar-sweetened beverage tax: the inconvenient truths." Public Health Nutrition 20(18):3225-3227.

Bandy, L.K., P. Scarborough, R.A. Harrington, M. Rayner, and S.A. Jebb. 2020. "Reductions in sugar sales from soft drinks in the UK from 2015 to 2018." BMC Medicine 18(1):20. Available at: https://bmcmedicine.biomedcentral.com/articles/10.1186/s12916-019-1477-4 [Accessed January 15, 2020].

BBC. 2016. "Sugar tax: What is the UK's most sugary drink?" Available at: https://www.bbc.co.uk/news/magazine-35831125 [Accessed January 14, 2020].

Buckton, C.H., G. Fergie, P. Leifeld, and S. Hilton. 2019. "A discourse network analysis of UK newspaper coverage of the 'sugar tax' debate before and after the announcement of the Soft Drinks Industry Levy." BMC Public Health 19(1):490. 
Buckton, C.H., C. Patterson, L. Hyseni, S.V. Katikireddi, F. Lloyd-Williams, A. Elliott-Green, S. Capewell, and S. Hilton. 2018. "The palatability of sugar-sweetened beverage taxation: A content analysis of newspaper coverage of the UK sugar debate" R. J. de Souza, ed. PLOS ONE 13(12):e0207576.

Cawley, J., A.M. Thow, K. Wen, and D. Frisvold. 2019. "The Economics of Taxes on Sugar-Sweetened Beverages: A Review of the Effects on Prices, Sales, Cross-Border Shopping, and Consumption." Annual Review of Nutrition 39(1):annurev-nutr-082018-124603.

Colchero, M.A., C.M. Guerrero-López, M. Molina, and J.A. Rivera. 2016. "Beverages Sales in Mexico before and after Implementation of a Sugar Sweetened Beverage Tax" F. Guerrero-Romero, ed. PLOS ONE 11(9):e0163463.

Euromonitor. 2019. "Passport Global Market Information Database." Euromonitor International.

Guerrero-López, C.M., M. Molina, and M.A. Colchero. 2017. “Employment changes associated with the introduction of taxes on sugar-sweetened beverages and nonessential energy-dense food in Mexico." Preventive Medicine 105:S43-\$49.

HM Treasury. 2016. "Soft Drinks Industry Levy: 12 things you should know." Available at: https://www.gov.uk/government/news/soft-drinks-industry-levy-12-things-you-should-know [Accessed August 28, 2019].

Imamura, F., L. O'Connor, Z. Ye, J. Mursu, Y. Hayashino, S.N. Bhupathiraju, and N.G. Forouhi. 2015. "Consumption of sugar sweetened beverages, artificially sweetened beverages, and fruit juice and incidence of type 2 diabetes: systematic review, meta-analysis, and estimation of population attributable fraction." BMJ (Clinical research ed.) 351:h3576.

Kontopantelis, E., T. Doran, D.A. Springate, I. Buchan, and D. Reeves. 2015. "Regression based quasiexperimental approach when randomisation is not an option: interrupted time series analysis." BMJ (Clinical research ed.) 350:h2750. Available at:

http://www.ncbi.nlm.nih.gov/pubmed/26058820 [Accessed January 14, 2020].

Lawman, H.G., S.N. Bleich, J. Yan, M.T. LeVasseur, N. Mitra, and C.A. Roberto. 2019. “Unemployment claims in Philadelphia one year after implementation of the sweetened beverage tax" S. Fu, ed. PLOS ONE 14(3):e0213218.

Malik, V.S., A. Pan, W.C. Willett, and F.B. Hu. 2013. "Sugar-sweetened beverages and weight gain in children and adults: a systematic review and meta-analysis." The American Journal of Clinical Nutrition 98(4):1084-1102.

Niederdeppe, J., S.E. Gollust, M.P. Jarlenski, A.M. Nathanson, and C.L. Barry. 2013. "News coverage of sugar-sweetened beverage taxes: pro- and antitax arguments in public discourse." American journal of public health 103(6):e92-8.

ONS. 2017. "Monthly Business Survey: improving the method for survey non-response." Available at: https://www.ons.gov.uk/economy/nationalaccounts/uksectoraccounts/articles/monthlybusine sssurveyimprovingthemethodforsurveynonresponse/2017-09-29 [Accessed August 28, 2019].

Oxford Economics. 2016. "The economic impact of the soft drinks levy."

Pell, D., T. Penney, D. Hammond, L. Vanderlee, M. White, and J. Adams. 2019. "Support for, and perceived effectiveness of, the UK soft drinks industry levy among UK adults: cross-sectional analysis of the International Food Policy Study." BMJ open 9(3):e026698.

Penney, T., J. Adams, and M. White. 2018. "LB4 Industry reactions to the UK soft drinks industry levy: unpacking the evolving discourse from announcement to implementation." In Oral 
presentations. Journal of Epidmiology \& Community Health, p. A43.1-A43.

Pomeranz, J.L., and M. Pertschuk. 2019. "Sugar-sweetened beverage taxation in the USA, state preemption of local efforts." Public Health Nutrition 22(1):190-190. Available at:

https://www.cambridge.org/core/product/identifier/S136898001800304X/type/journal_article [Accessed January 15, 2020].

Powell, L.M., R. Wada, J.J. Persky, and F.J. Chaloupka. 2014. "Employment impact of sugarsweetened beverage taxes." American journal of public health 104(4):672-7.

Public Health England. 2017. "Social Marketing Strategy 2017 to 2020." Available at: https://assets.publishing.service.gov.uk/government/uploads/system/uploads/attachment_dat a/file/646715/public_health_england_marketing_strategy_2017_to_2020.pdf [Accessed August 29, 2019].

Public Health England. 2015. "Sugar Reduction The evidence for action." Available at: https://assets.publishing.service.gov.uk/government/uploads/system/uploads/attachment_dat a/file/470179/Sugar_reduction_The_evidence_for_action.pdf [Accessed August 28, 2019].

The Grocer. 2019. "Lucozade Energy launches $f 10 \mathrm{~m}$ 'Spark Something' push." :17. Available at: https://www.thegrocer.co.uk/marketing/lucozade-energy-launches-10m-spark-somethingpush-/593477.article [Accessed January 15, 2020].

The Grocer. 2018. "Red Bull flies high as Lucozade Energy has wings clipped." Available at: https://www.thegrocer.co.uk/soft-drinks/red-bull-flies-high-as-lucozade-energy-has-wingsclipped/565880.article [Accessed January 15, 2020].

Xi, B., Y. Huang, K.H. Reilly, S. Li, R. Zheng, M.T. Barrio-Lopez, M.A. Martinez-Gonzalez, and D. Zhou. 2015. "Sugar-sweetened beverages and risk of hypertension and CVD: a dose-response metaanalysis." British Journal of Nutrition 113(5):709-717.

\section{Appendix}

A. Examples of non-diet drinks under each levy category (in March 2016)

\begin{tabular}{|l|l|}
\hline Levy category & Drinks \\
\hline f0.24 per litre for drinks with $\geq 8 \mathrm{~g}$ sugar per $100 \mathrm{ml}$ & Coca Cola, 7 Up, Lucozade Energy Original \\
\hline f0.18 per litre for drinks with 5-8g sugar per 100ml. & Fanta Orange, Sprite, Dr Pepper \\
\hline No tax for drinks with less than $5 \mathrm{~g}$ of sugar per 100ml & Tango Orange, Schweppes Lemonade \\
\hline
\end{tabular}

Source: BBC (2016)

B. ADF Unit root test results

\begin{tabular}{lccc}
\hline & $\ln$ (Drink) & InNonFD & InRPI \\
\hline Without trend & & & \\
5\% Critical value & -2.890 & -2.890 & -2.890 \\
Test Statistic & -3.761 & -4.881 & -2.579 \\
p-value & 0.003 & $<0.001$ & 0.097 \\
With trend & & & \\
$5 \%$ Critical value & -3.450 & -3.450 & -3.450 \\
Test Statistic & -6.161 & -9.485 & -2.695 \\
p-value & $<0.001$ & $<0.001$ & 0.238 \\
\hline
\end{tabular}




\section{Retail price index of soft drinks (February $2016=100$ )}

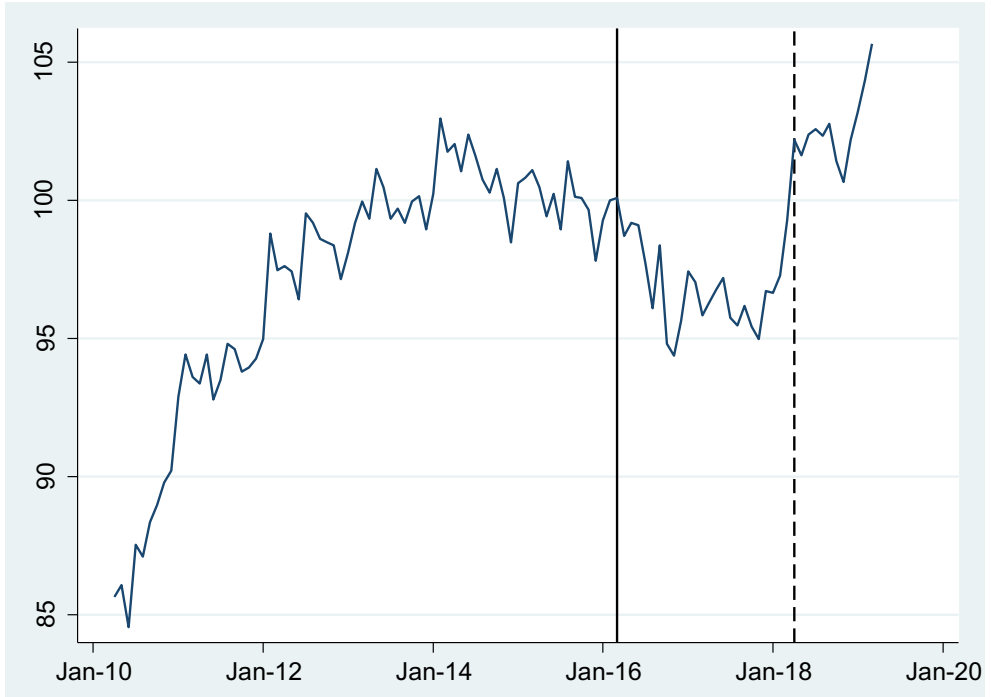

Note: The solid and dashed vertical lines indicate the SDIL announcement in March 2016 and the implementation in April 2018 respectively. Source: ONS

\section{Autocorrelations and partial correlation graphs for estimations in table 4}

\section{Model 1}

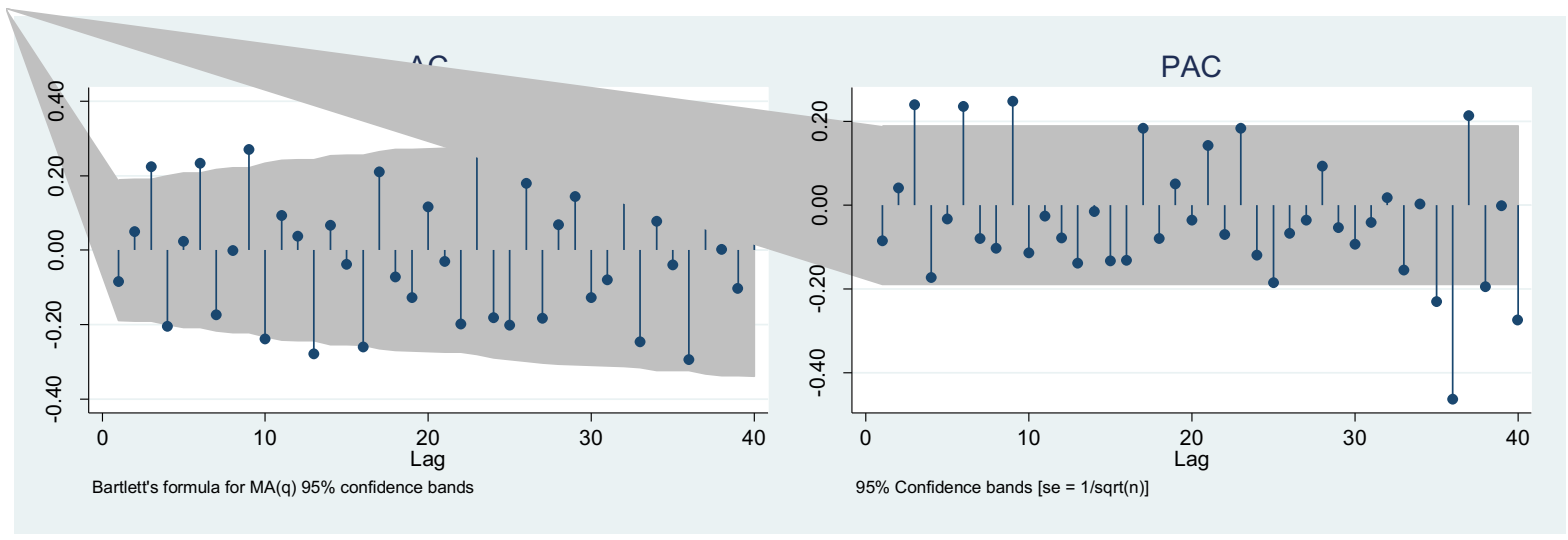

\section{Model 2}
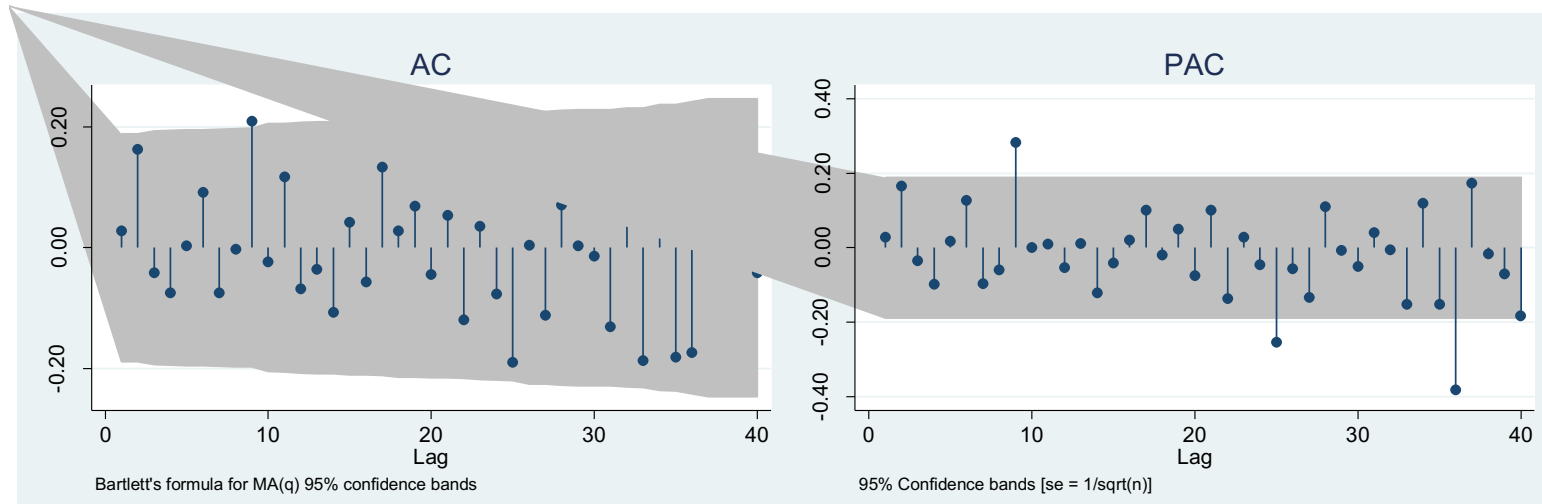


\section{Model 3}
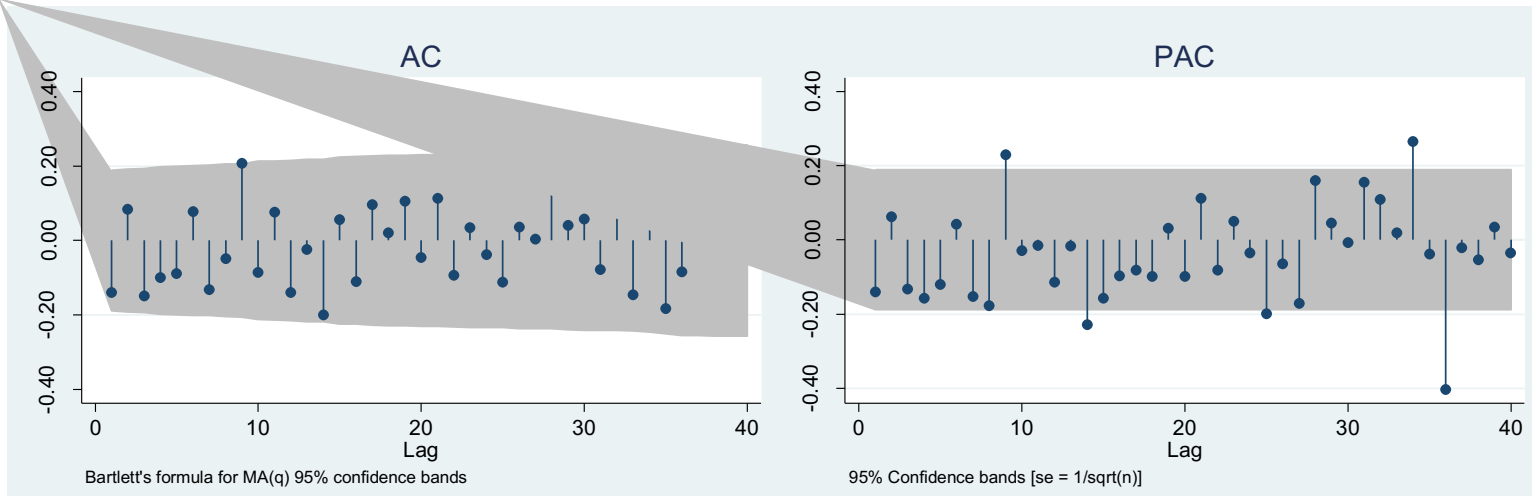

\section{E. Residual tests}

Table D1: Residual tests for unit roots and serial correlation for models in table 6

\begin{tabular}{|c|c|c|c|c|}
\hline & \multicolumn{4}{|c|}{ Models } \\
\hline & A1 & $\mathrm{A} 2$ & A3 & A4 \\
\hline \multicolumn{5}{|c|}{ 1. Dickey-Fuller test without trend } \\
\hline Test statistics & -10.000 & -10.311 & -8.581 & -6.514 \\
\hline P-value & $<0.001$ & $<0.001$ & $<0.001$ & $<0.001$ \\
\hline \multicolumn{5}{|c|}{ 2. Dickey-Fuller test with trend } \\
\hline Test statistics & -9.971 & -10.275 & -9.146 & -7.504 \\
\hline P-value & $<0.001$ & $<0.001$ & $<0.001$ & $<0.001$ \\
\hline \multicolumn{5}{|c|}{ 3. Phillips-Perron test without trend } \\
\hline Test statistics & -10.005 & -10.322 & -8.747 & -6.905 \\
\hline P-value & $<0.001$ & $<0.001$ & $<0.001$ & $<0.001$ \\
\hline \multicolumn{5}{|c|}{ 4. Phillips-Perron test with trend } \\
\hline Test statistics & -9.974 & -10.285 & -9.184 & -7.837 \\
\hline P-value & $<0.001$ & $<0.001$ & $<0.001$ & $<0.001$ \\
\hline \multicolumn{5}{|c|}{ 5. Breusch-Godfrey test (Prob> chi $\left.{ }^{2}\right)$} \\
\hline Lags (1) & 0.469 & 0.793 & 0.743 & 0.127 \\
\hline Lags (4) & 0.226 & 0.300 & 0.317 & 0.199 \\
\hline Lags (6) & 0.253 & 0.357 & 0.382 & 0.174 \\
\hline Lags (12) & 0.152 & 0.122 & 0.203 & 0.056 \\
\hline
\end{tabular}

Table D2: Residual tests for unit roots and serial correlation for models in table 7

\begin{tabular}{|c|c|c|c|c|}
\hline & \multicolumn{4}{|c|}{ Models } \\
\hline & I1 & 12 & 13 & 14 \\
\hline \multicolumn{5}{|l|}{ 1. Dickey-Fuller test without trend } \\
\hline Test statistics & -9.636 & -9.590 & -8.286 & -9.202 \\
\hline P-value & $<0.001$ & $<0.001$ & $<0.001$ & $<0.001$ \\
\hline 2. Dickey-Fuller test with trend & & & & \\
\hline
\end{tabular}




\begin{tabular}{|c|c|c|c|c|}
\hline Test statistics & -9.606 & -9.559 & -8.258 & -9.157 \\
\hline P-value & $<0.001$ & $<0.001$ & $<0.001$ & $<0.001$ \\
\hline \multicolumn{5}{|c|}{ 3. Phillips-Perron test without trend } \\
\hline Test statistics & -9.685 & -9.655 & -8.287 & -9.275 \\
\hline P-value & $<0.001$ & $<0.001$ & $<0.001$ & $<0.001$ \\
\hline \multicolumn{5}{|c|}{ 4. Phillips-Perron test with trend } \\
\hline Test statistics & -9.649 & -9.618 & -8.261 & -9.234 \\
\hline P-value & $<0.001$ & $<0.001$ & $<0.001$ & $<0.001$ \\
\hline \multicolumn{5}{|c|}{ 5. Breusch-Godfrey test (Prob> chi ${ }^{2}$ ) } \\
\hline Lags (1) & 0.310 & 0.299 & 0.250 & 0.937 \\
\hline Lags (4) & 0.159 & 0.145 & 0.141 & 0.060 \\
\hline Lags (6) & 0.118 & 0.100 & 0.175 & 0.056 \\
\hline Lags (12) & 0.076 & 0.063 & 0.417 & 0.296 \\
\hline
\end{tabular}

